Bolm Inst. oceanogr., S Paulo, 30(1):1-8, 1981

\title{
VARIAÇÃO DA COMPOSIÇÃO QUİMICA DO CAMARÃO PENAEUS (M.) BRASILIENSIS LATREILLE, DURANTE ESTOCAGEM NO GELO*
}

\author{
Sërgio Araüjo ANTUNES ${ }^{1}$; † Arthur F。 NOVAK ${ }^{2}$ \& Rodolpho de CAMARGO ${ }^{3}$
}

1 Instituto Oceanogräfico da Universidade de São Paulo

2 Louisiana State University, USA

3 Escola Superior de Agricultura "Luiz de Queiroz" da Universidade de São Paulo

Synops is

Changes were observed in shrimp during iced storage. Determinations were made on the moisture, protein, ash and trimethylamine content of the Penaeus (M.) brasiliensis, caught off the central southerm coast of Brazil. The changes are related to the length of the storage period, the size-sex relationship, and the degree of maturation of the female. The moisture and trimethylamine (TMA) content increased, and the protein and ash contents decreased during an extension of the iced storage time. For moisture and protein contents, the interaction time in iced storage was significant with size-sex relationship, and with the degree of maturation. An increase of TMA during iced storage was equivalent for both male and female species. However, it appeared to be greater for male specimens, becouse they reach the stage of TMA production ahead of the female.

\section{Introdução}

A composição química dos organismos marinhos, em particular os camarões, vem sendo estudada desde o final do século passado. Diversos fatores, porém, nela interferem, influindo no controle da qualidade na indústria, distribuição e biologia do próprio organismo.

0 presente trabalho procura dar uma contribuição ao conhecimento de alguns fatores de variação (estocagem em gelo, sexo-tamanho e maturação sexual), estudando o camarão Penaeus (M.) brasiliensis Latreille, 1817, espécie pouco conhecida em nosso meio e de grande importância econômica para o Brasil, principalmente por seu potencial de exportação.

* Parte da Tese de Doutorado de S。A. Antunes, Escola Superior de Agricultura "Luiz de Queiroz", 1970。 Pesquisa apresentada na "The Twenty-eight Southwest Regional Meeting", Baton Rouge, La., EUA, Dezembro, 1972。Este estudo foi financiado pela Fundação de Amparo à Pesquisa do Estado de São Pau10。

Publ. nọ 498 do Inst. oceanogr. da Usp.
Material e mētodos

o camarão utilizado, Penaeus (M.) brasiliensis Latreille, foi capturado na "Lage de Santos", costa centro-sul do Brasil. Os exemplares foram lavados a bordo de barco pesqueiro, resfriados com ge1o, estocados em condições comerciais e desembarcados num período de 24 horas. Após o desembarque, os camarões foram separados em grupos homogêneos, de acordo com sexo, grau de maturação e tamanho (Antunes, 1970)。Três classes foram estudadas: machos maduros, fêmeas imaturas, e em maturação. Foram separados $20 \mathrm{ca-}$ marões para cada classe, sendo distribuídos ao acaso em grupos de quatro, para cada período de estocagem. Cada uma dessas sub-amostras foi colocada em saco de malha de "nylon", permitindo contāto direto entre o camaráo e o gelo utilizado na estocagem, tomando cuidado adicional para assegurar separação total de cada camarão com gelo. Os sacos, após fechados e colocadas etiquetas com a indicação da classe e sub-amostras a que pertenciam, foram estocados em camadas alternadas de gelo e camarão, em caixas de isopor com $50 \times 40 \times 60 \mathrm{~cm}$ e $\operatorname{com} 5,0$ $\mathrm{cm}$ de espessura, revestidas com $2,0 \mathrm{~cm}$ 
Bolm Inst. oceanogr., S Paulo, 30(1), 1981

de madeira。 As mesmas foram cobertas por uma tampa de isopor com 5,0 cm de espessura e colocadas em câmara de estocagem do Terminal de Pesca de Santos, com temperatura abaixo de $10^{\circ} \mathrm{C}$. A intervalos regulares de três dias, retirou-se, para análise, uma sub-amostra de cada classe, com períodos de estocagem de $2,5,8,11$ e 14 dias, iniciados a partir da captura. 0 objetivo dos cuidados tomados na estocagem foi o de procurar expor igualmente todos os tratamentos ao gelo e impedir a seleção, por parte do amostrador, dos espécimes, ao serem efetuadas as sub-amostragens.

As anälises de proteina (nitrogênio total $\times 6,25)$, cinza e umidade foram efetuadas em replicatas ( $a$ e $b$ ), de acordo com métodos descritos no AOAC (1965). As operações de retirada dos filés foram feitas com o máximo de cuidado, através da retirada da cabeça, secção da porção dorsal do exoesqueleto e separação da carne, procurando evitar a introdução de substâncias estranhas à amostra e a perda de umidade da mesma. Os filés, logo após a retirada, foram colocados em copos-delaboratório, tampados com vidro de relógio, mantidos à temperatura de $0^{\circ} \mathrm{C}$ atē a posterior homogeneização。 Os teores de trimetilamina foram determinados pelo método de Dyer (1945), sendo a lei-tura feita em espectrofotômetro Spectronic 20 , da Bausch \& Lomb。

Os resultados de proteína, cinza e umidade foram transformados para valores arco-seno de acordo com Snedecor \& Cochran (1956) e submetidos à anälise da variância, segundo Pimentel Gomes (1966), segundo os seguintes modelos:

MODELO I:

$\begin{array}{lc} & \text { G.L。 } \\ \text { Tratamentos } & I-1 \\ \text { Tempo (T) } & t-1 \\ \text { Grupo (G) } & g-1 \\ \text { Interação T x G } & (\mathrm{t}-1)(\mathrm{g}-1) \\ \text { Resíduo } & (\mathrm{I}-1)(\mathrm{j}-1) \\ \text { Total } & \mathrm{Ij}-1 \\ \text { I Tratamentos....... t tempos } \times \text { g grupos } \\ \text { j repetições }\end{array}$

Nas anālises com interação T x G significativas, foi efetuado o desdobramento que segue:
MODELO II:

$\begin{array}{lc}\text { C. Variação } & \text { G。L。 } \\ \text { Tempo d. G1 } & t-1 \\ \text { Tempo d。G2 } & t-1 \\ \text { Tempo d. G3 } & t-1\end{array}$

Em todos os casos, a partir do modelo I ou II, o nümero de graus de liberdade (G.L。) do tempo de estocagem foi desdobrado para estudo de regressão, conforme modelo abaixo:

MODELO III:
R。 Linear
R. Quadrātica
1
R. Cübica
D. Regressão
1
$\mathrm{t}-4$
$t-1$

G.L。

As determinações de trimetilamina foram utilizadas apōs transformação de $10 \times 1 \circ g$ (1 + TMA), anteriormente aplicada por Shewan \& Ehrenberg (1957), Watanabe (1962) e Calabrese (1965), sendo selecionados os valores obtidos nos 50, 89 e 11 ? dias de estocagem. Esta medida tem por objetivo a utilização, para efeito de cálculo, das amostras que estavam no período de estocagem onde os acréscimos de trimetilamina eram mais acentuados.

Nesse período, o método tem sua significação como indicador da decomposição da carne do camarão (Fieger \& Friloux, 1954 e Bailey et al, 1956). Dessa maneira, foi excluído o período de estocagem anterior a este, no qual a quantidade de trimetilamina é praticamente constante; o método não tem significação como indicador da decomposição e a transformação de $10 \times 1$ og ( 1 + TMA) menos representativa. A dependência destes valores de trimetilamina ao período de estocagem em gelo foi expressa por meio de equações lineares $(y=a+b x)$, com coeficiente de correlação $r$, sendo o mesmo testado por:

$t=\frac{r}{\sqrt{1-r^{2}}} \sqrt{N-2}$

onde $G_{0} L_{\circ}=\mathrm{N}-2$

$\mathrm{N}=$ número de determinações efetuadas. 
As classes foram analisadas através da comparação entre suas regressões 1ineares, efetuada em conjunto de pares de dados $\left[y=f(x)\right.$ e $\left.y=f\left(x^{\prime}\right)\right]$, simultaneamente, por meio de teste " $t$ ", segundo Leme (1958)。 Esta comparação foi realizada em duas etapas:

1) Ver se eram paralelas, pela identidade ou não dos coeficientes de regressão

(B), e a ocorrência de igualdade nestes coeficientes;

2) Ver se as retas são coincidentes, pela comparação dos termos independentes das regressões (A)。

Os cälculos foram efetuados por meio de computador B。 3500 。

Resultados e discussão

Os resultados obtidos são apresentados na Tabela I e analisados nas Tabelas II-V。

Os teores de umidade e trimetilamina aumentam e os de proteína e cinza diminuem durante o período de estocagem (Tabs I-V). Foi constatado que, para os teores de proteína e umidade, ocorrem diferenças significativas entre os grupos analisados (machos, fêmeas imaturas e em maturação), porém o mesmo não foi evidenciado para as determinações de cinza. Observou-se que a análise da variância efetuada para a cinza não levou em consideração o ültimo período de estocagem (14 dias), devido à perda de observações, o que sem dúvida limitou esta constatação (Tabs I e IV)。

Verificou-se que, para as condições experimentais e para o período considerado nas anālises, o tempo de permanência dos camarões estocados em gelo influiu nos teores de trimetilamina das três classes consideradas.

$\mathrm{Na}$ Tabela $\mathrm{V}$ verifica-se que, ao nível de $5 \%$ de significância, as equações representativas das variações dos teores de trimetilamina, dos dois grupos de fêmeas considerados, não diferem entre si, pois, tanto o coeficiente de regressão como o termo independente, não são diferentes estatisticamente. Com base nestas verificações, as duas classes foram englobadas e obteve-se uma única equação representativa para as fêmeas, sendo a mesma diferente ao nível de $5 \%$ de significância da equação do macho. Esta distinção entre macho e fêmea somente foi observada com relação aos termos independentes, não diferindo com respeito à inclinação da reta。

Esta discordância das equações com relação ao parâmetro A, evidencia que na análise, durante o período considerado, ocorre uma diferença de trimetilamina ao nível de $5 \%$ de significância entre as comparações efetuadas, senđo que, no ca$\mathrm{so}$, os machos possuem maiores teores de trimetilamina que as fêmeas

A diferença não significativa entre as comparações, com relação ao coeficiente de regressão, mostraque os acréscimos de trimetilamina, durante o período considerado na anälise, não diferiram significativamente entre as classes macho/ fêmeas 。

Verificou-se, portanto, que os fatores em conjunto sexo-tamanho concorrem para que os exemplares machos, de menor porte e com maior superfície de exposição do camarão à ação do gelo e das bactërias, tivessem maior teor de trimetilamina no período considerado na anālise. A produção de trimetilamina deve ter iniciado primeiramente nos camarões machos, mantendo depois desenvolvimento próximo ao das fêmeas, por estarem submetidos ao mesmo sistema de estocagem。Anteriormente, Fieger \& Friloux (1954), com Penaeus aztecus e $P$. setiferus, da Louisiana, EUA, e Govidan (1962) com camarão na India, haviam observado que o tamanho dos espécimes de camarão estocados em gelo tinha influência nos teores de trimetila carne, apresentando os camarões de menor porte maior teor de trimetilamina, - que concorda com o observado no presente trabalho. Não foi encontrada referência anterior na literatura, indicando que os acrëscimos de trimetilamina não diferem significativamente entre camarões machos, de menor porte, e fêmeas imaturas e em maturação, durante o período de estocagem no gelo, no qual sua produção é mais acentuada.

Considerando esse período e comparando com o observado pelos demais autores, verificou-se que os resultados do presente estudo coincidem com os de Iyengar et al. (1960) e Collins et al. (1960) e que o aumento verificado ocorre em fase posterior ao observado por Fieger \& Friloux $(1954 a, b)$, Velankar et al。 (1961) e Bethea \& Ambrose (1961)。 Os resultados obtidos por Campbell \& Williams (1952) diferem dos observados no presente trabalho e dos obtidos pelos demais auto- 
Tabela I - Composição química da carne do camarão durante estocagem em gelo

\begin{tabular}{|c|c|c|c|c|c|c|c|c|c|c|c|c|c|}
\hline \multirow[b]{2}{*}{ st } & \multirow[b]{2}{*}{$5 x$} & \multirow[b]{2}{*}{ Nt } & \multicolumn{2}{|c|}{$\begin{array}{l}\text { Tamanho } \\
\text { (cm) }\end{array}$} & \multicolumn{2}{|c|}{$\begin{array}{c}\text { Peso } \\
(8)\end{array}$} & \multicolumn{2}{|c|}{$\begin{array}{l}\text { Umidade } \\
\text { (z) }\end{array}$} & \multicolumn{2}{|c|}{$\begin{array}{l}\text { Cinze } \\
\text { (z) }\end{array}$} & \multicolumn{2}{|c|}{$\begin{array}{l}\text { Proteinse } \\
\text { (x) }\end{array}$} & \multirow[t]{2}{*}{ THAmg/100g } \\
\hline & & & $t$ & c & $t$ & $m=$ & - & b & • & $b$ & • & b & \\
\hline \multirow[t]{12}{*}{2} & $n$ & m & 169 & 38 & 385 & 210 & 73,60 & 73,39 & 1.76 & 1,82 & 25.45 & 25,17 & \\
\hline & & & 172 & 39 & 435 & 236 & 73,67 & 73.57 & 1.77 & 1.93 & 25,28 & 24,92 & \\
\hline & & & 174 & 45 & 419 & 214 & 73.67 & 73.83 & 1,89 & 1.90 & 25,64 & 25.54 & \\
\hline & & & 174 & 39 & 403 & 222 & 73.53 & 73.60 & 1.80 & 1,83 & 25,58 & 25,21 & \\
\hline & $F$ & $m$ & 199 & 47 & 678 & 331 & 76,06 & 73,90 & 1,73 & 1,77 & 25,20 & 25,30 & \\
\hline & & & 197 & 48 & 715 & 312 & 72,70 & 72,97 & 1,70 & 1,80 & 26,14 & 26,27 & \\
\hline & & & 199 & 48 & 710 & 366 & 73.92 & 73,94 & 1,79 & 1.60 & 25,86 & 25,01 & \\
\hline & & & 206 & 52 & 832 & 332 & 75.18 & 75,17 & 1.79 & 1.76 & 24,17 & 25,43 & \\
\hline & $F$ & en & 200 & 48 & 656 & 343 & 74,67 & 76.63 & 1.72 & 1.79 & 25,26 & 24.71 & \\
\hline & & & 196 & 49 & 676 & 319 & 73.43 & 73,57 & 1,79 & 1.73 & 26,06 & 26,00 & \\
\hline & & & 207 & 50 & 776 & 395 & 74.29 & 73.47 & 1.74 & 1.56 & 25.09 & 25.10 & \\
\hline & & & 202 & 50 & 674 & 328 & 74,88 & 74.20 & 1.99 & 2.11 & 24,47 & 25.21 & \\
\hline \multirow[t]{12}{*}{5} & $n$ & $m$ & 172 & 39 & 444 & 242 & 76,37 & 76,16 & 1.52 & 1,63 & 22,11 & 22,82 & 1.50 \\
\hline & & & 177 & 41 & 486 & 258 & 76,99 & 76,61 & 1,47 & 1,43 & 22,07 & 22.55 & 1.30 \\
\hline & & & 172 & 38 & 422 & 228 & 76,17 & 75,70 & 1.53 & 1.53 & 22.65 & 22.54 & 1.60 \\
\hline & & & 170 & 39 & 426 & 219 & 76,13 & 75.00 & 1.67 & 1,80 & 22.73 & 22,31 & 1.60 \\
\hline & $f$ & m & 197 & 46 & 678 & 300 & 75,07 & 74,18 & 1,73 & 1,63 & 23,87 & 24,05 & 0,80 \\
\hline & & & 210 & 52 & 824 & 363 & 75.16 & 75,67 & 1,56 & 1,66 & 23,36 & 22,67 & 0,80 \\
\hline & & & 209 & 51 & 800 & 368 & 76.06 & 76,37 & 1,53 & 1,43 & 22,42 & 22.20 & 0.40 \\
\hline & & & 215 & 52 & 880 & 391 & 75.83 & 75,59 & 1.56 & 1,66 & 22.61 & 22.75 & 0,20 \\
\hline & $F$ & em & & 52 & 810 & 403 & 75.57 & 75,45 & 1.73 & 1.86 & 23.73 & 23.57 & 0.60 \\
\hline & & & 197 & 50 & 756 & 357 & 75,82 & 76,15 & 1.60 & 1.57 & 23.43 & 23.96 & 0.60 \\
\hline & & & 207 & 51 & 796 & 395 & 75.73 & 75,21 & 1,66 & 1,70 & 23.67 & 23.45 & 0,60 \\
\hline & & & 205 & 53 & 816 & 390 & 76,22 & 75.83 & 1,47 & 1.43 & 23,02 & 22,96 & 0,60 \\
\hline 8 & $n$ & $m$ & 174 & 40 & 481 & 265 & 77.32 & 76,50 & 1.53 & 1,59 & 21.97 & 22,45 & 9.60 \\
\hline & & & 171 & 37 & 419 & 229 & 78,98 & 79,13 & 1,16 & 1.33 & 21.65 & 20,43 & 9.60 \\
\hline & & & 171 & 37 & 426 & 232 & 77.54 & 77.41 & 1.60 & 1.46 & 22,10 & 23.05 & 9,20 \\
\hline & & & 172 & 38 & 423 & 231 & 77.55 & 77.54 & 1,47 & 1,42 & 22,14 & 22,51 & 10,80 \\
\hline & $F$ & $m$ & 203 & so & 807 & 350 & 75,46 & 75,81 & 1,76 & 1.80 & 22,33 & 22.54 & 5,00 \\
\hline & & & 202 & 51 & 790 & 359 & 77.51 & 76,44 & 1,69 & 1.65 & 21,76 & 21,91 & 5.00 \\
\hline & & & 201 & 49 & 759 & 396 & 78.86 & 78.82 & 1.53 & 1,36 & 20,60 & 21.01 & 4,00 \\
\hline & & & 202 & 50 & 759 & 364 & 77.88 & 77.63 & 1.54 & 1,38 & 21.28 & 21,43 & 4,40 \\
\hline & $F$ & em & & 51 & 831 & 414 & 78.17 & 77.74 & 1.46 & 1.47 & 20,37 & 21.25 & 4.20 \\
\hline & & & 207 & 51 & 844 & 414 & 77.57 & 78,20 & 1.53 & 1,64 & 20.50 & 21.00 & 5,60 \\
\hline & & & 197 & 49 & 712 & 352 & 78.80 & 78.80 & 1,37 & 1.69 & 20,64 & 20.41 & 5.20 \\
\hline & & & & 52 & 881 & 622 & 77.72 & 78,02 & 1.47 & 1.30 & 21,26 & 20,98 & 5.40 \\
\hline 11 & $n$ & $m$ & 180 & 41 & 496 & 272 & 80,07 & 80,37 & 1,00 & 1.03 & 19.34 & 19.42 & 24.00 \\
\hline & & & 180 & 39 & 462 & 258 & 80.07 & & 1,36 & 1,17 & 19.78 & 20.15 & 24,00 \\
\hline & & & 182 & 40 & 470 & 263 & 78.72 & 78.30 & 1.20 & 1.40 & 21,04 & $20 \quad 34$ & 46.00 \\
\hline & & & 175 & 39 & 431 & 222 & 80.65 & 80.65 & 1.13 & 1.00 & 18,59 & 18,49 & 44,00 \\
\hline & $F$ & $=$ & 216 & 52 & 873 & 436 & 77.55 & 77.06 & 1.60 & 1.32 & 21.28 & 20,64 & 19.60 \\
\hline & & & 215 & 52 & 844 & 552 & 79.12 & 78,96 & 1,13 & & 21.65 & 20.66 & 19.60 \\
\hline & & & 212 & 51 & 786 & 381 & 77.41 & 77.16 & 1.40 & 1,23 & 22,83 & 22,61 & 22,80 \\
\hline & & & 210 & 50 & 188 & 581 & 78.55 & 77.61 & 1,13 & 1,23 & 21,29 & 21,52 & 22,00 \\
\hline & r & em & 207 & 52 & 868 & 410 & 78.32 & 78,70 & 1.23 & 1.22 & 19.30 & 20,08 & 21,20 \\
\hline & & & 205 & 50 & 798 & 393 & 79.05 & 79.27 & 1,26 & 1.10 & 20.95 & 21.45 & 18,40 \\
\hline & & & & 50 & 763 & 350 & 78,30 & 77.67 & 1,13 & 1,10 & 20.57 & 21.04 & 23,20 \\
\hline & & & & 47 & 627 & 369 & 71,83 & 77.92 & 1,39 & 1.23 & 20,78 & 21.70 & 22,80 \\
\hline 14 & $n$ & m & 177 & 60 & 463 & 225 & 81.01 & 80,82 & 1.03 & 1.03 & 18.98 & 19.19 & \\
\hline & & & 174 & 45 & 654 & 234 & 79.71 & 80,16 & 1.26 & 1,20 & 19.59 & 20,23 & \\
\hline & & & 172 & 39 & 474 & 267 & 81.59 & 81.28 & 0.86 & 0,90 & 18,84 & 18,51 & \\
\hline & & & 170 & 41 & 461 & 269 & 80.73 & 80.74 & & & 18,29 & 19,79 & \\
\hline & $F$ & $m$ & 210 & 52 & 846 & 407 & 79.82 & 80.51 & & & 19.94 & 20,03 & \\
\hline & & & 202 & 49 & 814 & 371 & 30,60 & 79.97 & & & 20,60 & 20,53 & \\
\hline & & & 201 & 50 & 783 & 383 & 79.80 & 79.96 & & & 20,10 & 20,22 & \\
\hline & & & 202 & 49 & 766 & $3+7$ & 79.46 & 79,28 & & & 20,14 & 20,56 & \\
\hline & 5 & en & 200 & 51 & 827 & 395 & 79.82 & 80,06 & 0,93 & 1.07 & 19.61 & 20,21 & \\
\hline & & & 176 & 42 & 534 & 283 & 79,43 & 79,70 & 1.10 & 1,13 & 20.58 & 20,82 & \\
\hline & & & & & & 390 & 79,85 & 19.66 & 0,96 & 1,37 & 20,53 & 20.58 & \\
\hline & & & & & & 394 & 80,03 & 79.86 & 1,43 & 1,07 & 21,09 & 20.87 & \\
\hline
\end{tabular}

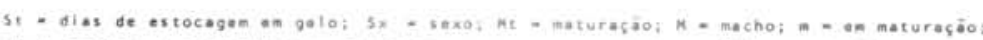




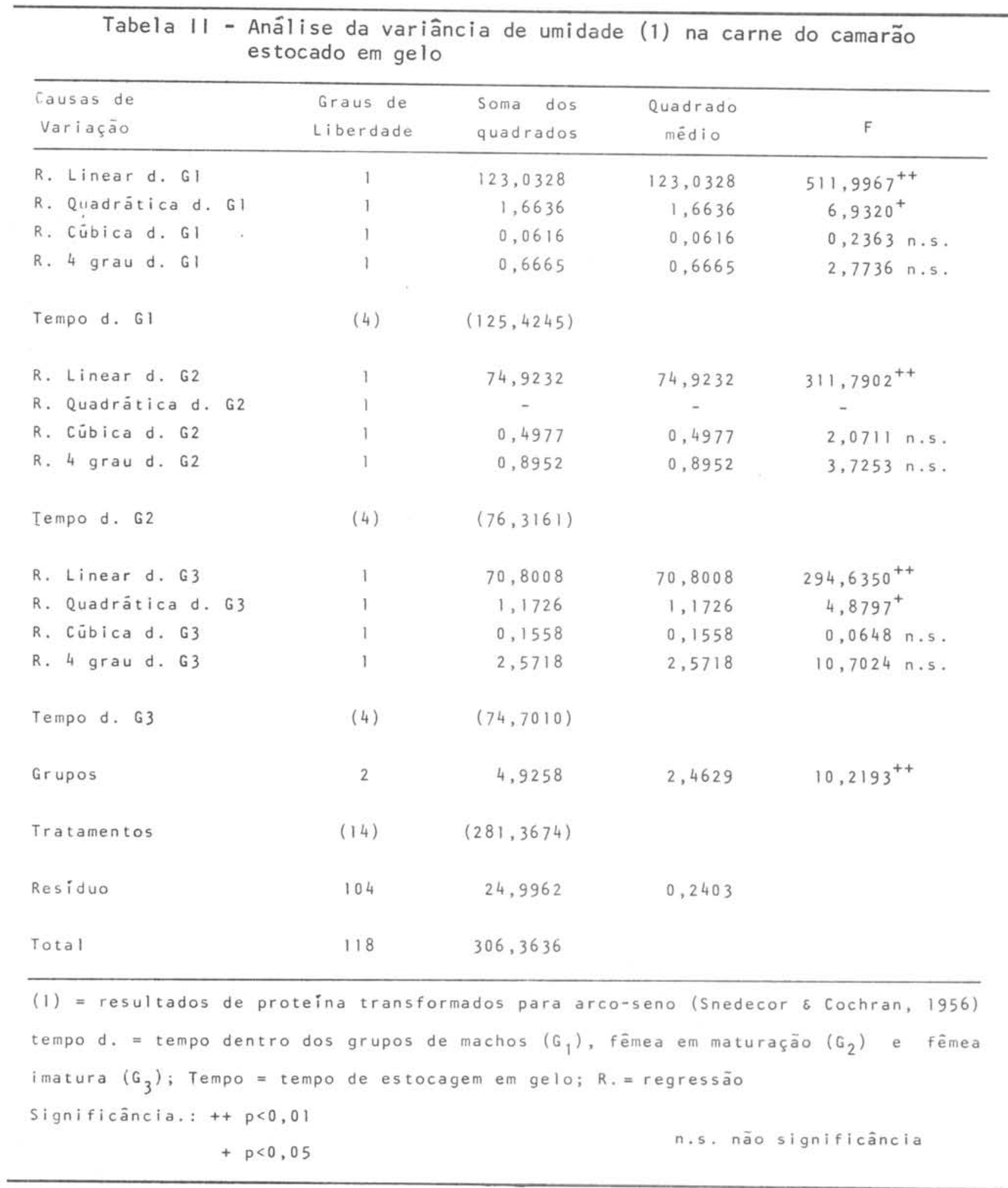

res que estudaram o assunto. Podem ser considerados como exceções decorrentes de condições particulares ao experimento realizado por aqueles autores。

\section{Resumo}

Este estudo apresenta variações, durante a estocagem em gelo, dos teores de umidade, proteína, cinza e trimetilamina na carne de camarões Penaeus $\left(M_{0}\right)$ brasiliensis Latreille, capturado na costa centrosul do Brasil. As mudanças estão relacionadas com o período de estocagem, relação sexo-tamanho e grau de maturação das fêmeas, sendo observadas interações significativas para umidade e proteína.

Os teores de umidade e trimetilamina aumentam e os de proteína e cinza de- 
Bolm Inst. oceanogr., S Paulo, 30(1), 1981

Tabela III - Anälise da variância de proteína (1) na carne do
camarão estocado em gelo

\begin{tabular}{|c|c|c|c|c|}
\hline R. Linear d. GI & 1 & 88,9365 & 88,9365 & $514,9768^{++}$ \\
\hline R. Quadrätica d. Gi & 1 & 2,0656 & 2,0656 & $11,9606^{++}$ \\
\hline R. Cübica d. Gl & 1 & 0,0720 & 0,0720 & 0,4169 n.s. \\
\hline R. 4 grau d. GI & 1 & 3,8247 & 3,8247 & $22,2038^{++}$ \\
\hline Tempo d. Gl & (4) & $(94,8988)$ & & \\
\hline R. Linear d. $G 2$ & 1 & 51,8581 & 51,8581 & $300,2785^{++}$ \\
\hline R. Quadräticad. 62 & 1 & 3,1793 & 3,1793 & $18,4094^{++}$ \\
\hline R. Cübica d. $G 2$ & 1 & 1,9782 & 1,9782 & $11,4545^{++}$ \\
\hline R. 4 grau d. G2 & 1 & 0,4537 & 0,4537 & $2,6271 \mathrm{n.s}$. \\
\hline Tempo d. $G 2$ & (4) & $(57,4693)$ & & \\
\hline R. Linear d. 63 & 1 & 56,3808 & 56,3808 & $326,4667^{++}$ \\
\hline R. Quadrática d. 63 & 1 & 7,9929 & 7,9929 & $46,2820^{++}$ \\
\hline R. Cübica d. G3 & 1 & 0,3277 & 0,3277 & 1,8975 n.s. \\
\hline R. 4 graud. 63 & 1 & 2,0691 & 2,0691 & $11,9809^{++}$ \\
\hline Tempo d. G3 & (4) & $(66,7705)$ & & \\
\hline Grupos & 2 & 4,2424 & 2,1212 & $12,2826^{++}$ \\
\hline Tratamentos & (14) & $(223,3810)$ & & \\
\hline Residuo & 105 & 18,1356 & 0,1727 & \\
\hline Total & 119 & 241,5166 & & \\
\hline
\end{tabular}

(1) = resultados de proteina transformados para arco-seno (Snedecor E Cochran, 1956) tempo $d .=$ tempo dentro dos grupos de machos $\left(G_{1}\right)$, fêmea em maturação $\left(G_{2}\right)$ e fêmea imatura $\left(G_{3}\right)$; Tempo = tempo de estocagem em gelo; R. = regressão.

Significância.: $++p<0,01$

$+p<0,05$

n.s. nāo significância

crescem, durante a extensão do período de estocagem. 0 acrēscimo de trimetilamina foi equivalente para macho e fềmea; no entanto, o mesmo aparenta ser maior para os espécimes machos, porque os mesmos atingem o estāgio de produção de trimetilamina antes que as fêmeas, provavelmente devido ao seu menor porte e, consequentemente, maior superfície de exposição à ação do gelo e bactérias. A influência do tamanho dos camarões na produção de trimetilamina durante a estocagem em gelo já havia sido observada por Fieger \& Friloux (1954) e Govidan (1962), nos EUA e India, respectivamente, porém esta è a primeira evidência de que os acréscimos de trimetilamina não diferem significativamente entre machos, de menor porte, e fêmeas, imaturas e em maturação. 
Tabela IV - Anälise da variância de cinza (1) na carne do camarão
estocado em gelo

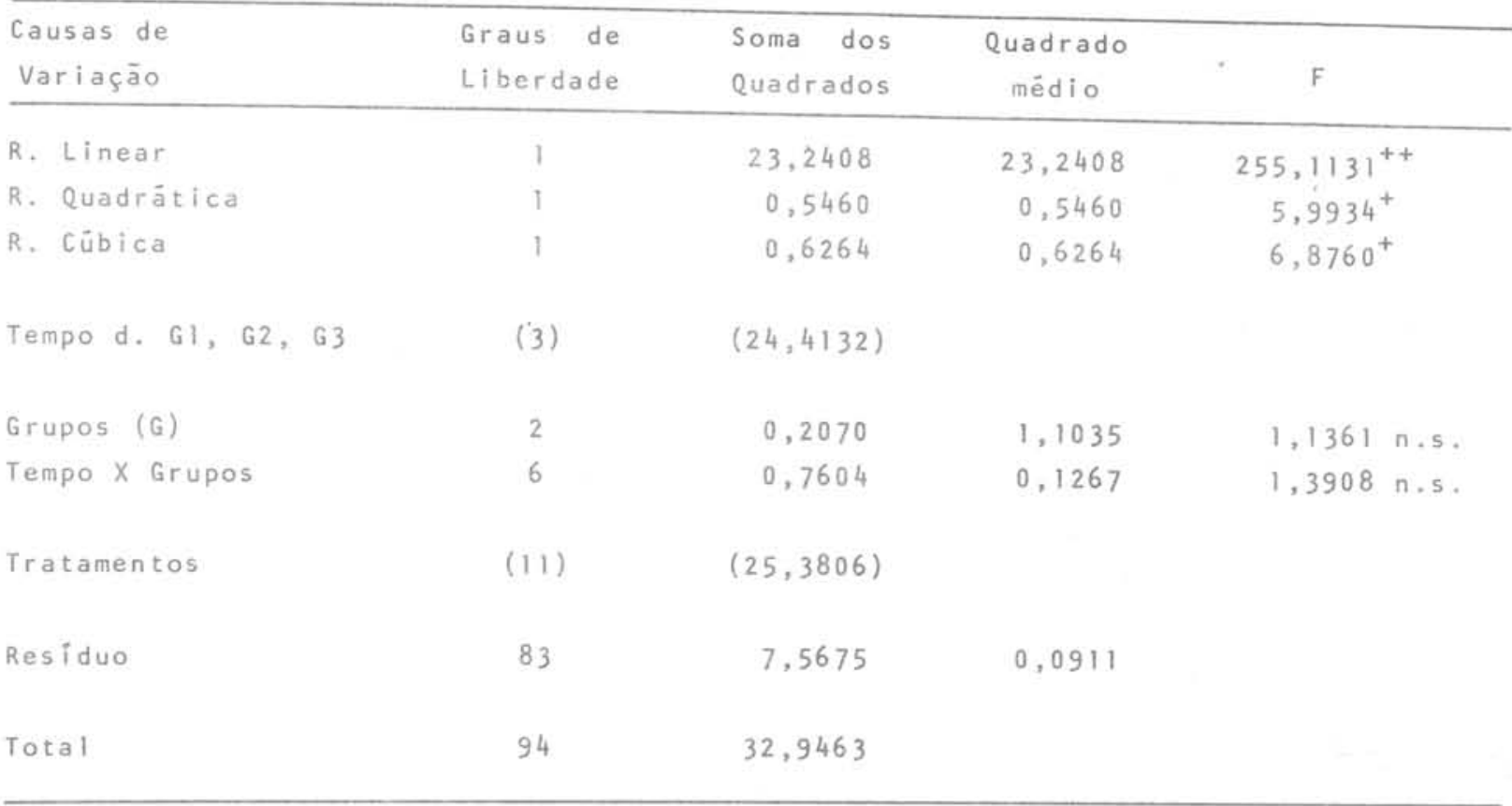

$(1)=$ resultados de cinza transformados para arco-seno (Snedecor \& Cochran, 1956) Tempo d. = tempo dentro dos grupos de machos $\left(G_{1}\right)$, fêmea em maturação $\left(G_{2}\right)$ e fêmea imatura $\left(G_{3}\right)$;

Significância.: ++ $p<0,01 \quad$ n.s. nāo significância

$+p<0,05$

Tabela V - Regressões de trimetilamina (1) na carne do camarão e dias de estocagem em gelo. Comparação entre diferentes classes

\begin{tabular}{|c|c|c|c|c|c|}
\hline Determinação & $\mathrm{N}$ & $r$ & $t(r)$ & & Equações \\
\hline Macho & 12 & 0,98 & 15,53 & $y=$ & $-5,19+1,88 \times$ \\
\hline Fêmea em maturação & 12 & 0,99 & 31,30 & $y=$ & $-7,86+1,93 x$ \\
\hline Fêmea imatura & 12 & 0,99 & 31,30 & $y=$ & $-7,47+1,91 \times$ \\
\hline Grupo de duas fêmeas & 24 & 0,99 & 33,14 & $y=$ & $-7,67+1,92 \times$ \\
\hline Comparaçāo entre classes & NI & tA & $t B$ & & Conclusāo \\
\hline Macho $x$ fêmea em maturaçäo & 24 & $2,974^{+*}$ & 0,061 & n.s. & Diferente em $A$ \\
\hline Macho x fêmea imatura & 24 & $2,553^{++}$ & 0,034 & $\mathrm{n} \cdot \mathrm{s}$. & Diferente em $A$ \\
\hline Fêmeas: imatura $x$ em maturação & 24 & $0,430 \mathrm{n} . \mathrm{s}$. & 0,027 & n.s. & Näo diferente \\
\hline Macho x grupo de fêmeas & 36 & $3,204^{++}$ & 0,055 & n.s. & Diferente em $A$ \\
\hline
\end{tabular}

N, N1 = nümero de determinaçöes efetuadas

(1) resultados de TMA apresentados como $10 \times \log (1+T M A) ; y=$ no qual TMA em $\mathrm{mg} / 100 \mathrm{~g}$ de carne de camarão

$x=$ dias de estocagem; significância: ++ $p<0,01$ 
Bolm Inst. oceanogr., S Paulo, 30(1), 1981

\section{Agradecimentos}

Os autores apresentam sinceros agradecimentos à Dra. Martha Vannucci, DiretorGeral do Instituto Oceanogräfico da USP na época do desenvolvimento do trabalho, por sua ajuda e incentivo, e ao $\mathrm{Dr}$. Alfredo Martins Paiva Filho, pela colaboração 。

\section{Referências bibliogråficas}

ANTUNES, S。A。1970. Contribuição ao estudo de alguns fatores que ocasionam variação na composição química do camarão Penaeus (M.) brasiliensis Latreille capturado nas águas da costa centro-sul do Brasil. Tese de Doutorado. Universidade de São Paulo, Escola Superior de Agricultura "Luiz de Queiroz", 126p。

AOAC - ASSOCIATION OF OFFICIAL AGRICULTURAL CHEMISTRY。1965。 Official methods of analysis $10^{\text {th }} \mathrm{ed}$. Washing ton D。C., p. 15-16, 272-274.

BAILEY, M。E.; FIEGER, E. A。 \& NOVAK, A. F. 1956. Objective tests applicable to quality studies of ice stored shrimp. Food Res。, 21(6):611-620.

BETHEA, S。 \& AMBROSE, M。E. 1961. Physical and chemical properties of shrimp drip as indices of quality. Comm. Fish。Rev。, 23(1):9-14.

CALABRESE, R. H。1965。Valoración de 1a frescura de la merluza mediante la determinación de trimetilamina y tirosina. Segundo Congreso bonaerense Prom。 Pesq., :1-24.

CAMPBELl, L。 L. \& WILliams, O. B. 1952. The bacteriology of Gulf coast shrimp. IV. Bacteriological, chemical and organoleptic changes with icestorage. Food Tech。, 6(4): 125-126.

COLLINS, J.; SEAGRAN, H。 \& IVERSON, J。 1960. Processing and quality studies of shrimp held in refrigerated sea water and ice. Part 2-Comparison of objective methods for quality evaluation of raw shrimp. Comm.Fish. Rev., $22(4): 1-5$.

DYER, W。 J。 1945. Amines in fish muscle. I. Colorimetric determin- ation of trimethylamine as the picrate salt。 J. Fish. Res. Bd Can。, 6(5):351-358。

FIEGER, E。A。\& FRILOUX, J. J。 1954a. Comparison of objective tests for quality of Gulf shrimp. Food Tech。, $8(1): 35-38$ 。

$1954 b$.

Comparison of objective tests for quality of fresh and frozen Gulf shrimp。 Proc. Gulf Caribb. Fish. Inst., $6^{\text {th }} \mathrm{A}$. sec $0: 1-7$.

IYENGAR, J。R •; VISWESWARIAH, K。; MOORJANI, M. N. \& BHATIA, D。S。 1960. Assessment of the progressive spoilage of ice-stored shrimp. J。Fish. Res。 Bd Can。, 17(4):475-485。

GOVIDAN, T. K。 1962. Some new indices of quality for ice stored prawns.Sci. Cult。, 28:36-37.

LEME, R. A. da S. 1958. Curso de estatística.São Paulo, Escola Politécnica da Universidade de São Paulo, v。 2, p.13.83-13.97.

PIMENTEL GOMES, F。1966。 Curso de estatística experimental。3a ed。 Piracicaba, Universidade de São Paulo, p.295-313 (mimeografado)。

SHEWAN, J. M. \& EHRENBERG, A。 S. C。 1957. Volatile bases as quality indices of ice north cod. J。 Sci. Fd Agric。, 8(4):227-231。

SNEDECOR, G. W. \& COCHRAN, W。 Go 1956. Statistical methods. 5th ed. Iowa State Univ. Press, p. 318319.

VELANKAR, N. K.; APPUKUTTAN, P. N. \& MAHADEVA IYER, K. 1961. Spoilage of prawns at $0^{\circ} \mathrm{C}$ and its assessment by chemical and bacteriological tests. Indian J. Fish., 8(1):241-251。

WATANABE, K. 1962. Spoilage in iced "pescada-foguete" (Macrodon ancylodon) from south Brazilian fishing grounds. Bolm Inst, oceanogr,, S Paulo, 12(2): 65-77. 